\title{
Cuerpos marcados: prostitución, literatura y derecho
}

\author{
Daniela Paula Bianchi (2019). Buenos Aires, Didot, 334 pp.
}

๑ Sofía B. Lamarca

UBA

La literatura latinoamericana, tan heterogénea y sensible a los matices como lxs mismxs sujetxs latinoamericanxs y del Abya Yala, ha tratado, problematizado, discutido y puesto en foco los distintos escenarios de la violencia sobre los cuerpos y las existencias de las mujeres. El libro de Paula Daniela Bianchi, Cuerpos marcados: prostitución, literatura y derecho (2019) propone un objeto y un abordaje poco trabajados en la crítica literaria latinoamericana. La figura literaria de la prostituta, como sujeto complejo y diverso en sus representaciones, es la protagonista de lo que la autora llama "ficciones prostitucionales" que serán, a su vez, los objetos de crítica de su primer libro. En ese sentido, es preciso detenerse en la propia elección del corpus, que abarca una diversidad de relatos de escritoras latinoamericanas y que, según la misma autora "pueden leerse como relatos de lo político, es decir, como ficciones que activan dispositivos políticos respecto de los variados modos en que se instaura lo social en la literatura" (Bianchi, 2019: 27).

El libro, de cinco capítulos, está estructurado en dos partes: una introducción teórico-metodológica, y una segunda parte aplicada al análisis literario del corpus. El primer capítulo, dedicado a la introducción de los conceptos centrales del libro y a sus discusiones teóricas, no es solo un listado de referencias, puntos de partida y antecedentes de investigación, sino que también, con una indudable vocación docente, proporciona herramientas y ejes de lectura para pensar las problemáticas referidas a la prostitución en particular, y a la ciudadanía, el estado, y la sexualidad en un sentido más amplio. La ciudadanía, y todo aquello que aparece por fuera de ella, es una de las categorías que articulan el libro en su totalidad, y aparece definida como problemática, como carencia y como limitación. Construida a partir de un universal masculino blanco y de clase alta, la plena ciudadanía del siglo XX excluye a las mujeres y a las diversidades sexo-genéricas. Para la autora, el mecanismo expulsivo del derecho moderno en pos de una conformación nacional se ve reflejado, también, en el campo literario. Ese cruce entre literatura y derecho (civil y penal), atravesado por las corporalidades y sus derivas en primer plano, es una de las apuestas fundamentales de Cuerpos marcados. El trabajo que la autora realiza sobre el cuerpo, más allá de una breve genealogía del término, está relacionado, en principio, con la prostitución y también con el acceso a la ciudadanía, es decir, quiénes son expulsados y descartados por los sistemas estatales. Así, las fronteras son un territorio de disputa y una categoría de productividad teórica y crítica para la línea de investigación de Bianchi. Las fronteras corporales, las de las naciones latinoamericanas, aquellas que problematizan territorialización y desterritorialización son móviles y están pensadas, en términos de Deleuze y Guattari, como rizomas. En cuanto a la prostitución, la autora plantea claramente su postura. Sin embargo, hace una exposición de las principales ideas alrededor de la prostitución y el trabajo sexual, recorriendo la amplitud de los posicionamientos al respecto. Recorre y analiza las propuestas de distintas teóricas, a la vez que diferencia a víctimas de trata, personas en situación de prostitución y trabajadoras sexuales. El tratamiento es teórica y epistemológicamente respetuoso, y el desarrollo de los argumentos es equilibrado. Se trata de un estudio y de una reconstrucción de saberes a partir de un abordaje interdisciplinario que no escapa a las contradicciones, sino que las expone y las habita. Se propone, en consonancia con todo el texto, explorar la productividad del análisis de los matices. La prostitución aparece, en esta instancia, debatida sociológica y antropológicamente, con el objetivo de dar cuenta de los debates contemporáneos y para entender luego cómo funcionan estas subjetividades en los procedimientos literarios. En esta introducción se pone de manifiesto de qué manera el libro 
está fundamentado en una articulación de saberes, proporcionando una lectura interdisciplinaria de los estudios de género. Es, en palabras de Nora Domínguez en su prólogo, "un libro-investigación, un libro-historia, un libro-saber y un libro-herramienta" (13).

La segunda parte del libro, articulada de manera coherente con la primera, desarrolla en cuatro capítulos un estudio de las obras propuestas a partir de los ejes teóricos y metodológicos establecidos en la introducción. Si bien cada apartado analiza minuciosamente una obra, se permite también la puesta en relación con otras ficciones latinoamericanas, entendiendo la literatura como un sistema que enriquece su análisis en la intertextualidad y la constelación. En el capítulo 2, "Ciudadanías militarizadas, desobediencias performativas", tiene como obra central Nadie me verá llorar, de Cristina Rivera Garza. Este capítulo explora las fronteras de la sexualidad y de la configuración del género, acompañando el constante movimiento y las entradas y salidas de Matilda, el personaje de la novela. En relación con otros textos latinoamericanos, este apartado problematiza los contextos dictatoriales y su repercusión sobre los cuerpos por fuera del territorio moral de lo nacional, específicamente, las prostitutas. Paula Bianchi afirma que las prostitutas literarias que analiza están atravesadas por un derecho punitivo que condena su existencia y a la vez las consume, configurándolas como subjetividades "dislocadas". El capítulo analiza de qué manera las narraciones construyen fronteras dentro y fuera de la misma subjetividad, dando espacio y protagonismo para las fugas a la heteronormatividad y en resistencia a los mecanismos que la conformación nacional y el derecho penal ejercen sobre el desvío. "El cuerpo como sede de negocios" es el capítulo 3 del libro y tiene como eje la novela Fuerzas especiales de Diamela Eltit. Forma parte central del corpus no tanto por la temática desarrollada en la ficción sino por los recursos, los discursos y los procedimientos estéticos que la novela elige para la narración. Bianchi entiende que el modo punzante en que es usado el lenguaje en voz de la protagonista intenta responder a la violencia que marcan los cuerpos que allí se representan. Como indica el nombre del capítulo, las corporalidades están narradas como un territorio de disputa y comercio, pero también de negociación, no solo en términos monetarios sino de supervivencia. Las fuerzas violentas del Estado se configuran como un oponente central en el relato y es allí donde la autora de Cuerpos marcados vislumbra la potencia de los modos estéticos utilizados para narrar la violencia. En cuanto al mercado sexual, se propone también un corpus de otrxs autorxs latinoamericanxs, que configuran distintos tipos de trabajadoras sexuales y otros modos de violencia, generando así, una serie literaria que puede ser analizada a la luz de los conceptos de "mercado" y "negociación".

El capítulo 4, "Quien a hierro mata a hierro muere" tiene como texto disparador Beya (le viste la cara a Dios), la novela gráfica de Gabriela Cabezón Cámara. Aquí, también en relación con otros relatos, se trabaja el núcleo narrativo de la huida y el escape. El cuerpo "quebrado" de la protagonista de la novela principal, explotado con fines sexuales, es también un cuerpo-venganza que se mantiene vivo por la pulsión de la huida. El capítulo analiza el desarrollo de los personajes a través de las figuras de legítima defensa y de justicia, afianzando la relación entre derecho y literatura que se propone el libro. Huida y cautiverio, violencia y venganza, justicia e injusticia son los tópicos por los que circula este apartado, con una mirada atenta sobre el derecho penal y los matices que la literatura permite. Este capítulo proporciona, a su vez, un análisis de un caso de la vida real, pero desde la perspectiva de la ficcionalización que la prensa hizo de la figura protagonista. Este representa un movimiento interesante y novedoso para la crítica literaria, en el que se lee la transformación en personaje de un sujeto real, atravesado por el delito. El capítulo finaliza, siguiendo el recorrido de la conformación de ciudadanías y extranjerías de lo nacional, con una propuesta de lectura que tiene al matadero contemporáneo como un espacio de violencia brutal. A través de las metáforas de la carne, mediada por la premisa de Viñas de una literatura que inicia con una escena de violación y atendiendo a los recursos de la elipsis y lo no dicho, el capítulo configura una serie literaria diversa, apelando a intertextualidades críticas y dando cuenta, fundamentalmente, de los vínculos producidos entre derecho y literatura.

El último capítulo, dividido al interior por epígrafes de ficciones, trabaja con los personajes femeninos que se posicionan en los matices destotalizadores a los que aludía el texto de manera sostenida. Se trata de un "por fuera del canon" que no ignora las salvedades que las hipótesis centrales de Cuerpos marcados proponen, sino que las desarrolla y las piensa a la luz de las múltiples subjetividades y derivas prostitucionales que las ficciones analizadas proponen. El último párrafo, que es también el cierre del libro, adopta un tono tan teórico como activista, con un claro deseo de resistencia y de ampliación de derechos. 
Cuerpos marcados: prostitución, literatura y derecho recurre a la marca no solo como símbolo de estigma, violencia y prisión, sino que también trabaja sobre la marca como delimitación de los márgenes. A partir del concepto de ciudadanía, central en todo el trabajo de Bianchi, se tejen sentidos sobre aquellos cuerpos que escapan, y que quedan por fuera de esa denominación jurídica y existencial. "Descarte", "baldío" y "expulsión" parecen ser los destinos más comunes para las corporalidades protagonistas de las ficciones trabajadas en este libro. Esto responde a una pregunta que la autora insinúa a lo largo de todo el análisis y se pone de manifiesto claramente en el último capítulo: ¿qué sucede después de la violencia? ¿Qué posibilidades hay después de la resistencia, del escape, de la huida? Son preguntas que, más allá y más acá de la ficción, reflexionan de manera profunda sobre la libertad, la soledad y el silencio, a la vez que problematizan cierto exitismo. Ese lugar baldío que aparece como el escenario de Ixs sujetxs sin ciudadanía es también el espacio de las mujeres protagonistas una vez que encuentran la vía de escape. ¿No hay posibilidad de comunidad en el cuarto propio? ¿Lo que queda después de la violencia es la soledad? Coherente con el tratamiento del marco teórico y su propio estudio de las obras del corpus, no hay respuestas totalizadoras. Con generosidad intelectual, el libro abre los interrogantes para ser pensados a la luz de otras literaturas, de otras ficciones, de otros análisis. 
